\title{
X-ray spectroscopy of hot solid density plasmas produced by subpicosecond high contrast laser pulses at $10^{18}-10^{19} \mathrm{~W} / \mathrm{cm}^{2}$
}

\author{
Z. Jiang, ${ }^{a)}$ J. C. Kieffer, J. P. Matte, and M. Chaker \\ Institut National de la Recherche Scientifique, Energie et Matériaux, 1650 Montée Saint Julie, Varennes, \\ Québec J3X 1S2, Canada
}

O. Peyrusse and D. Gilles

Commissariat a l'Energie Atomique, Limeil Center, Villeneuve, St. Georges, France

G. Korn, ${ }^{\text {b) }}$ A. Maksimchuk, S. Coe, and G. Mourou

Center for Ultrafast Optical Science, University of Michigan, Ann Arbor, Michigan 48109

(Received 26 October 1994; accepted 25 January 1995)

\begin{abstract}
Analysis is presented of $\mathrm{K}$-shell spectra obtained from solid density plasmas produced by a high contrast $\left(10^{10}: 1\right)$ subpicosecond laser pulse $(0.5 \mu \mathrm{m})$ at $10^{18}-10^{19} \mathrm{~W} / \mathrm{cm}^{2}$. Stark broadening measurements of He-like and Li-like lines are used to infer the mean electron density at which emission takes place. The measurements indicate that there is an optimum condition to produce $x$-ray emission at solid density for a given isoelectronic sequence, and that the window of optimum conditions to obtain simultaneously the shortest and the brightest $x$-ray pulse at a given wavelength is relatively narrow. Lower intensity produces a short $x$-ray pulse but low brightness. The $x$-ray yield (and also the energy fraction in hot electrons) increases with the laser intensity, but above some laser intensity $\left(10^{18} \mathrm{~W} / \mathrm{cm}^{2}\right.$ for $\mathrm{Al}$ ) the plasma is overdriven: during the expansion, the plasma is still hot enough to emit, so that emission occurs at lower density and lasts much longer. Energy transport measurements indicate that approximately $6 \%$ of the laser energy is coupled to the target at $10^{18}$ W/cm $\mathrm{cm}^{2}$ ( $1 \%$ in thermal electrons with $T_{e} \approx 0.6 \mathrm{keV}$ and $5 \%$ in suprathermal electrons with $T_{h} \approx 25$ $\mathrm{keV}$ ). At $I \lambda^{2}=10^{18} \mathrm{~W} \mu \mathrm{m}^{2} / \mathrm{cm}^{2}$ (no prepulse) around $10^{10}$ photons are emitted per laser shot, in $2 \pi$ srd in cold $K_{\alpha}$ radiation (2-9 $\AA$, depending on the target material) and up to $2 \times 10^{\mathrm{Il}}$ photons are obtained in $2 \pi$ srd with the unresolved transition array (UTA) emission from the Ta target. (C) 1995 American Institute of Physics.
\end{abstract}

\section{INTRODUCTION}

During the last 15 years, laser-produced plasmas have been extensively studied for, among other aspects, their potential application to inertial confinement fusion (ICF). Nanosecond laser pulses were used to realize laser-driven ablative implosion in which high compression can occur. In this scheme a pellet is accelerated inwardly by the reaction force associated with the outward expanding ablated material. Very inhomogeneous plasmas with characteristic dimensions, the electron density gradient scale length, for instance, very large compared to the laser wavelength are thus produced. Although laser irradiation with $I \lambda^{2}$ values up to $10^{18}$ $\mathrm{W} \mu \mathrm{m}^{2} / \mathrm{cm}^{2}$ has been realized with long-wavelength $\mathrm{CO}_{2}$ lasers, ${ }^{2}$ most of the recent experiments of interest for ICF have been realized with short-wavelength lasers $(\lambda<1 \mu \mathrm{m})$ at relatively moderate intensity $\left(I \lambda^{2}<10^{15} \mathrm{~W} \mu \mathrm{m}^{2} / \mathrm{cm}^{2}\right)$ to, among other problems, maximize the collisional absorption and reduce suprathermal electron preheat. ${ }^{3}$

A recent breakthrough in the laser amplification technique ${ }^{4}$ has allowed the generation of small-scale laser system with a peak power well into the terawatt regime and $I \lambda^{2}$ values greater than $10^{18} \mathrm{~W} \mu \mathrm{m}^{2} / \mathrm{cm}^{2}$, and plans for petawatt class picosecond lasers are actively pursued. ${ }^{5}$ This increase in peak power and irradiance, which has been made

\footnotetext{
${ }^{a}$ On leave from the Shanghai Institute of Optics and Fine Mechanics, Chinese Academy of Sciences, Shanghai, People's Republic of China.

bs On leave from Max-Born Institut, Berlin, Germany.
}

possible by the use of the technique of chirped pulse amplification (CPA), ${ }^{6}$ gives access to new regimes of interaction of laser with solid matter. ${ }^{7-9}$ The application of these intense subpicosecond pulses originates from a few fundamental features. The first is the short pulse duration, which noticeably limits plasma hydrodynamics during the heating phase. ${ }^{10}$ If there is negligible energy in the prepulse (high contrast), then the electron density gradient scale length is much shorter than the wavelength and the coupling takes place at near solid density. Many works on subpicosecond laser solid matter interaction have concentrated up to now on generating short pulses of $x$ rays, ${ }^{11-15}$ and the related transient and nonlocal atomic physics has been explored. ${ }^{16-18}$ The second feature is the extremely high-energy density and the resulting extremely high radiation pressure of the pulse. Laser intensities have long been sufficient to modify the plasma significantly at the critical density $\left(n_{c}=1.12 \times 10^{21} \lambda^{-2} \mathrm{~cm}^{-3}, \lambda\right.$ is the laser wavelength in $\mu \mathrm{m}$ ) by what is termed the ponderomotive force. ${ }^{19}$ With intense short pulses the radiation pressure can be quite large, ${ }^{20}$ even for electron density well above $n_{c}$, producing craters and going on to hole boring. ${ }^{21,22}$ These effects are relevant to the concept of fast ignition recently introduced by the Lawrence Livermore National Laboratory. ${ }^{23}$ In addition, new phenomena, such as the generation of far-infrared radiation, ${ }^{24}$ ion collimation, ${ }^{25}$ and strongly coupled Raman instability, ${ }^{26}$ have been observed, and short pulses incident on preformed plasmas have been 
used to study Brillouin scattering instability ${ }^{27}$ and nonlocal transport. ${ }^{28}$

In this paper we discuss some key issues related to the challenging problem of producing one dimension, hot, uniform solid density plasmas. Results are very promising for the achievement of isochoric heating (the term used to indicate heating at constant density) of matter at near solid density, up to extreme temperatures. Production of matter in such a state will offer a unique way to address experimentally in the laboratory some problems of great astrophysical interests, namely the opacity of hot dense matter ${ }^{29}$ and the physics of hot strongly correlated plasmas. ${ }^{30}$ Furthermore, this is also of importance for atomic physics, and will give us the possibility to study, among other aspects, (i) the ionization dynamics in hot dense plasmas with many electron atoms, ${ }^{31}$ (ii) the physics of quasimolecular states, ${ }^{32}$ and (iii) the statistical physics of hot strongly correlated plasmas. These plasmas will be also very interesting as ultrafast and ultrabright sources of short-wavelength radiation, which may have applications in many different fields as $\mathrm{x}$-ray laser physics, ${ }^{33}$ molecular sciences, ${ }^{34}$ and medical research. ${ }^{35}$

\section{CRITICAL ELEMENTS FOR SOLID DENSITY PLASMAS}

In the present work we try to combine ultrashort gradient scale length plasmas, or solid density, and very high laser intensity. The aim of these experiments is to explore the possibility of using the radiation pressure of a very high contrast subpicosecond pulse to balance the dense plasma's thermal pressure during the laser heating. Optimization is required: the intensity must be sufficient for the radiation pressure to prevent plasma expansion, but not as high as to lead to hole boring. ${ }^{21}$ The ultimate plasma we need to do clean experiments is ideally hot (electron temperature in the $\mathrm{keV}$ range) still (ions at rest) and at solid density $\left(n_{e}=6 \times 10^{23} \mathrm{~cm}^{-3}\right.$ for Li-like solid Al, for instance). Producing such a plasma therefore requires (i) a strict control of several crucial laser pulse parameters, (ii) detailed target design, and (iii) an excellent experimental characterization of the plasma.

For the particular problem of forming a hot solid density nearly uniform plasma, the key laser pulse issues are (i) a high contrast ratio to avoid any expansion of the matter before the main pulse arrival and (ii) an optimal pulse duration and high intensity $\left(10^{17}-10^{19} \mathrm{~W} / \mathrm{cm}^{2}\right)$.

While high intensities for short pulse duration are features obtained with the technology of chirped pulse amplification, an undesirable hy-product of this technology is the production, at the wavelength of $1 \mu \mathrm{m}$, of a long prepulse at very low relative intensity (typically $10^{-6}$ of the main pulse). ${ }^{36}$ This contrast of $10^{6}$ is not adequate at the intensity of interest here, where a contrast of something like $10^{10}$ is required to avoid excessive energy deposition at lower density in the preplasma created by the long prepulse.

The experiments were carried out with the table top terawatt $\left(\mathrm{T}^{3}\right)$ laser system at the University of Michigan. ${ }^{37}$ The laser delivered up to $2 \mathrm{~J}$ in a $400 \mathrm{fs}$ pulse at the wavelength of $1.053 \mu \mathrm{m}$. The intensity peak to background contrast ratio was measured to be $5 \times 10^{5}$ at $1.053 \mu \mathrm{m}$. The contrast has been improved to an estimated $10^{10}$ in our experiments by using the second harmonic generation (i.c., conversion to a green light) in nonlinear crystals, which will not double the weak prepulse. By using a potassium dihydrogen phosphate (KDP) type I crystal, we have been able to obtain a maximum conversion efficiency of $85 \% .{ }^{37}$ The 300 fs green pulse was focused with $45^{\circ}$ incidence angle off-axis $f / 3$ parabola. An optical system, composed of five dichroic mirrors and one $1 \mu \mathrm{m}$ filter, has been used to completely reject the unconverted $1 \mu \mathrm{m}$ radiation that could produce a preplasma. The intensity profile of the focal spot was measured with a magnifying imaging system $(40 \times)$ and a digital EG\&G twodimensional charge-couplcd-device (CCD) camera. The diameter of the spot size was found to be around $8 \mu \mathrm{m}$ at $(1 / e)^{2}$ intensity (that contains $65 \%$ of input energy); provided the laser energy on target is less than $900 \mathrm{~mJ}$. Above this value, the focal spot starts to be degraded by an excessive $B$ integral effect. Thus, in the present experiments we have used a maximum energy of $900 \mathrm{~mJ}$ in a $300 \mathrm{fs}$ green pulse, giving three terawatts on the target with no prepulse, and a maximum intensity of $4 \times 10^{18} \mathrm{~W} / \mathrm{cm}^{2}$ corresponding to $I \lambda^{2}=10^{18} \mathrm{~W} \mu \mathrm{m}^{2} / \mathrm{cm}^{2}$. To our knowledge, these experiments are the first in this intensity regime, with such a high contrast, short-wavelength subpicosecond laser.

\section{K-SHELL AI SPECTROSCOPY}

Plasma spectroscopy, which contributed to advances in inertial confinement fusion research, provides much of the information of these new high-density ultrashort plasmas. Johann and Von Hamos crystal spectrometers were used at $45^{\circ}$ from the laser axis to record the time-integrated $\mathrm{keV}$ spectra,

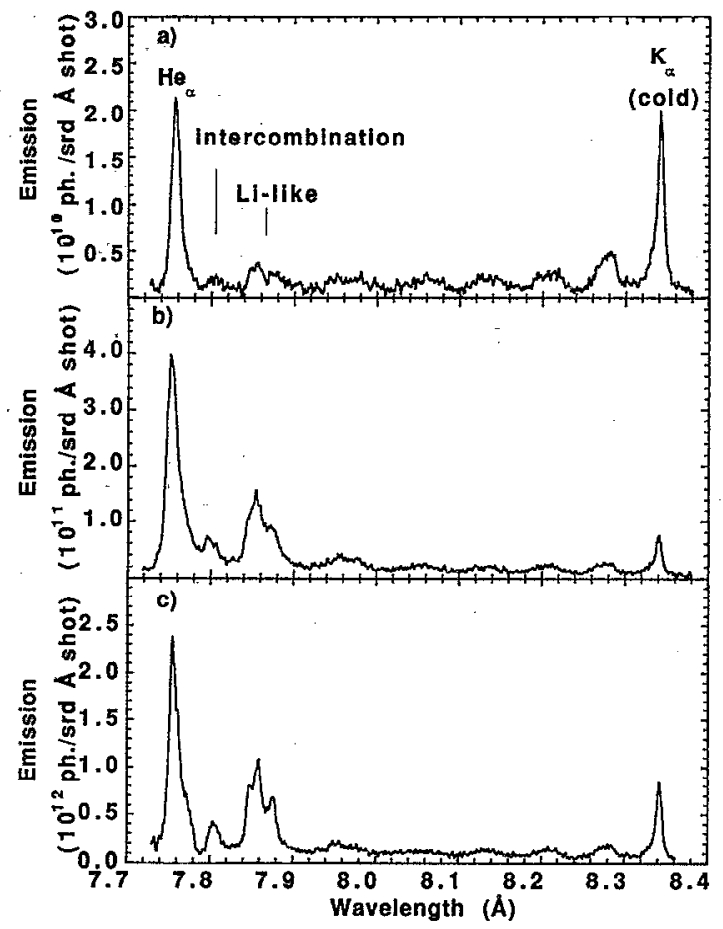

FIG. 1. Al spectra in 7.7-8.4 $\AA$ obtained with a high contrast subpicosecond laser pulse incident on $130 \mu \mathrm{m} \mathrm{Al}$ target. (a) $20 \mathrm{~mJ}, 10^{17} \mathrm{~W} / \mathrm{cm}^{2}$; (b) $150 \mathrm{~mJ}$, $7.7 \times 10^{17} \mathrm{~W} / \mathrm{cm}^{2}$; and (c) $710 \mathrm{~mJ}, 3.5 \times 10^{18} \mathrm{~W} / \mathrm{cm}^{2}$. 


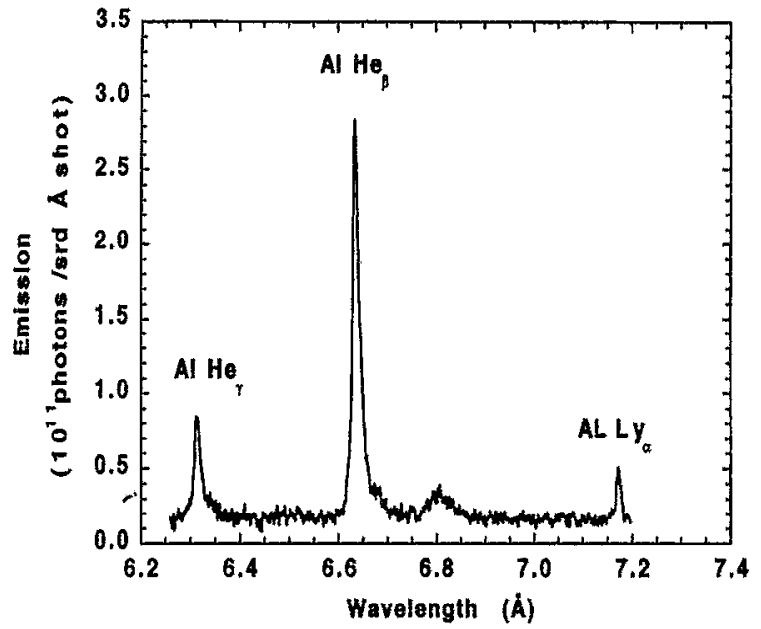

FIG. 2. He-like and $\mathrm{H}$-like lines in the $6.5 \AA$ range of $\mathrm{Al}$ plasma produced by $2.5 \times 10^{18} \mathrm{~W} / \mathrm{cm}^{2}$ laser pulse incident on a $130 \mu \mathrm{m}$ Al target. The line ratio of $\mathrm{Ly}_{\alpha} / \mathrm{He}_{\beta}$ is used to deduce the average electron temperature, which is around $600 \mathrm{eV}$ in our experimental conditions.

in the 1-10 $\AA$ range, with SB5 and DEF Kodak films. The thickness of Be filters in front of the film was adjusted as a function of the wavelength to avoid the saturation of the brightest line in a given wavelength detection window. Our crystal spectrometers provide high resolution spectra $(\lambda / \Delta \lambda$ of 2000-4000) for detailed studies of line shapes.

Figure 1 presents Al spectra $(7.7-8.4 \AA)$ obtained at $10^{17}$ W/cm ${ }^{2}$ [Fig. 1(a), $20 \mathrm{~mJ}$ on target], $7.7 \times 10^{17} \mathrm{~W} / \mathrm{cm}^{2}$ [Fig. 1 (b), $150 \mathrm{~mJ}$ ], and $3.5 \times 10^{18} \mathrm{~W} / \mathrm{cm}^{2}$ [Fig. 1(c), $630 \mathrm{~mJ}$ ]. The observed spectra have been corrected for the film, ${ }^{38}$ filter, ${ }^{39}$ and crystal response. ${ }^{40}$ At lower intensity [Fig, 1(a)], the $1 s^{2}-1 s 2 p$ emission $\left(\mathrm{He}_{\alpha}\right)$ from the thermal plasma is relatively low, and the emission is dominated by $\mathrm{K}_{\alpha}$ lines. We observe both the $\mathrm{K}_{\alpha}$ line from cold aluminum $\left(\mathrm{Al}^{0+}-\mathrm{Al}^{4+}\right.$ transitions are blended) and shifted $\mathrm{K}_{\alpha}$ lines corresponding to various ionization states from $\mathrm{Al}^{5+}$ to $\mathrm{Al}^{9+}$. This spectrum indicates that a low-temperature plasma was produced at low laser intensity. As the laser intensity is increased, the temperature, and thus the thermal emission, rapidly increases [Figs. 1(b) and $1(\mathrm{c})]$. Above $10^{18} \mathrm{~W} / \mathrm{cm}^{2}$, noticeable $\mathrm{Ly} \mathrm{y}_{\alpha}$ H-like emission is observed. A typical spectrum in the $6.5 \AA$ range, including the transitions from $\mathrm{He}$ - and $\mathrm{H}$-like ions states is shown in Fig. 2 (irradiance at $2.5 \times 10^{18} \mathrm{~W} / \mathrm{cm}^{2}$ ). The $\mathrm{He}_{\beta}$ and $\mathrm{He} \mathrm{e}_{\gamma}$ line profiles are used to infer the mean electron density at which the emissions take place. The $\mathrm{Ly}_{\alpha} / \mathrm{He}_{\beta}$ line ratio is around 0.35 at this intensity, and can provide a means of determining the electron temperature. The $\mathrm{He}$ - and $\mathrm{Li}$-like line shapes and $\mathrm{Ly} / \mathrm{He}_{\beta}$ intensity ratio are discussed in the next section.

\section{AVERAGE ELECTRON DENSITY}

The average electron density at which the emission takes place is inferred from various line profiles calculated by using the standard hypotheses of Stark line broadening by plasma, ${ }^{41}$ i.e., quasistatic approximations for the ions and impact approximation for the electrons. One aspect of our line shape calculations is the use of analytic fits of the plasma microfield distribution function, deduced from a large number of Monte Carlo simulations, ${ }^{42}$ performed with a Yukawa potential and a linearized Thomas-Fermi electron screening. In the range of plasma conditions where $\mathrm{K}$-shell lines are emitted, this formulation of the ion-ion potential agrees very well with a more sophisticated self-consistent formulation. ${ }^{43}$ The analytic fit that we use depends on the ionic correlation parameter (depending on $T_{i}$ ) and on the screening parameter (depending on $T_{e}$ ), and thus are a twotemperature formulation of the microfield distribution function. As noted elsewhere, ${ }^{44}$ this detail is important, since the microfield can be very sensitive to the temperature ratio $T_{e} / T_{i}$. Then the profile depends mainly on two unknown parameters, the electron density $n_{e}$, and the ion temperature $T_{i}$, if the density range is such (typically $n_{e}<10^{23} \mathrm{~cm}^{-3}$ ) that the thermal relaxation rate is lower than the radiative rate of the upper state of the transition of interest. A previous study of the $\mathrm{He}_{\gamma}\left(1 s^{2}-1 s 4 p\right)$ line profile in similar experimental conditions ( $2 \omega$ irradiation, no prepulse, $\left.5 \times 10^{17} \mathrm{~W} / \mathrm{cm}^{2}\right)^{45}$ indicated an ion temperature much lower than the electron temperature and a relatively high density at which $\mathrm{He}_{\gamma}$ emis-
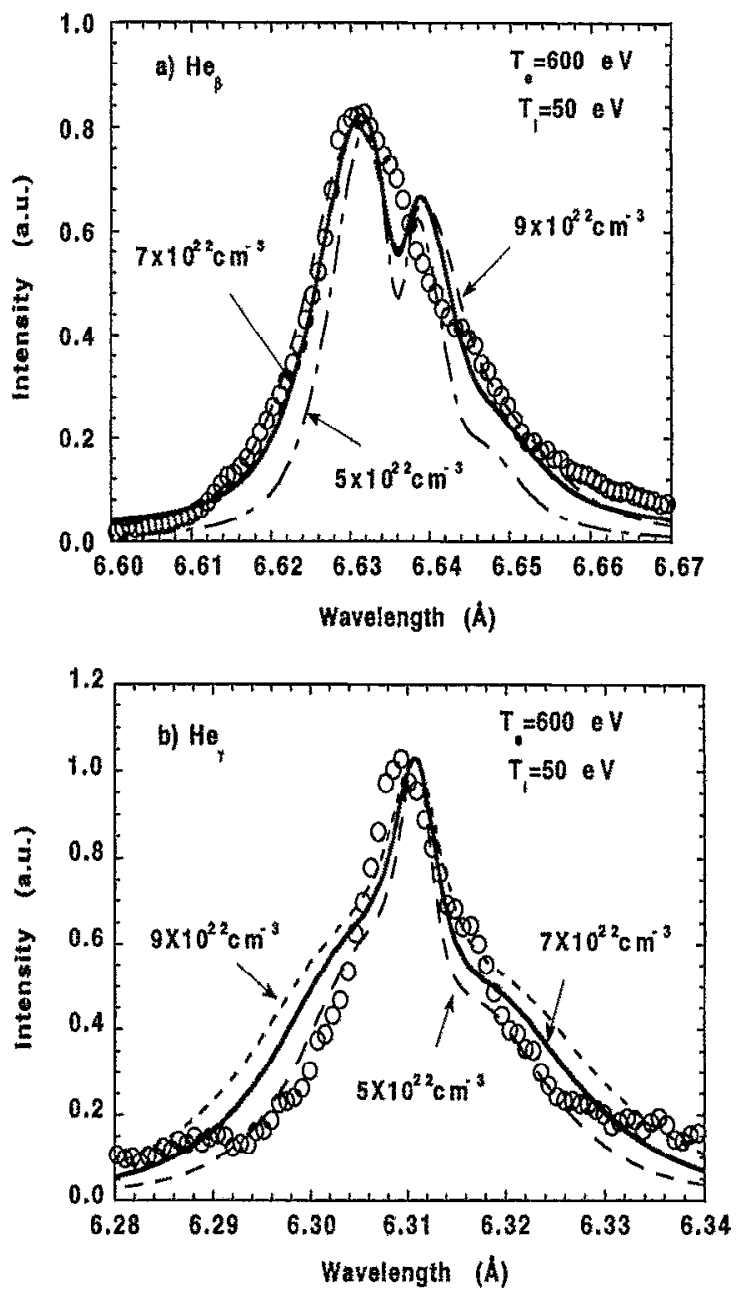

FIG. 3. Profiles of He-like lines of a $130 \mu \mathrm{m} \mathrm{Al}$ target. The laser intensity is $3 \times 10^{18} \mathrm{~W} / \mathrm{cm}^{2}$. The open dots are experimental data. The best fit (solid lines) to the data are using standard Stark broadening calculation (see the text) with the following parameters: $T_{e}=600 \mathrm{eV}, T_{i}=30-60 \mathrm{eV}$, and $n_{e}=5-7 \times 10^{22} \mathrm{~cm}^{-3}$. (a) $\mathrm{He}_{\beta}$ line and (b) $\mathrm{He}_{\gamma}$ line. 

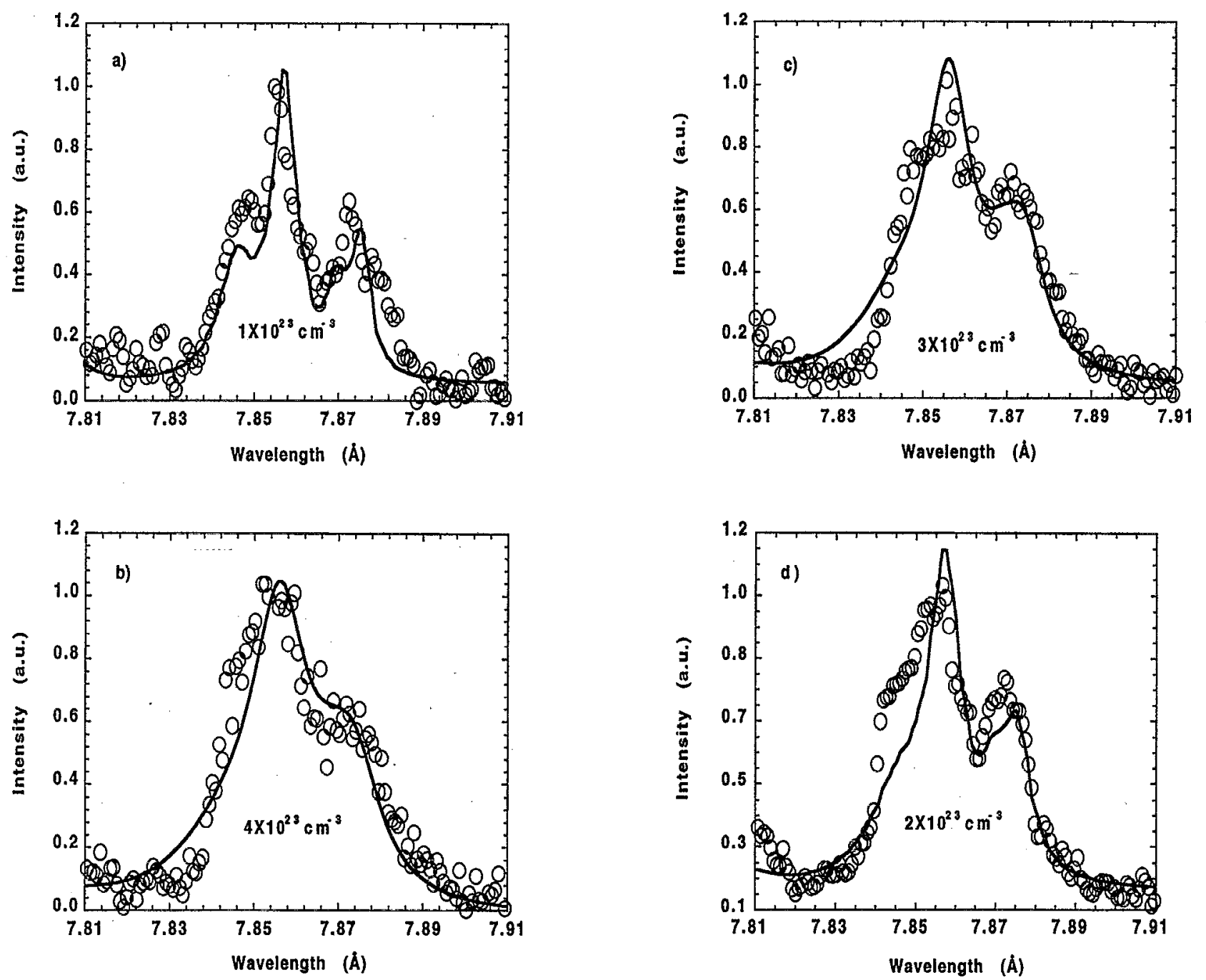

FIG. 4. The profiles of $\mathrm{Li}$-like lines of $130 \mu \mathrm{m} \mathrm{Al}$ target obtained with different laser intensities. The experimental data (open dots) are fitted (solid lines) with LTE Li-like line profile calculation and the inferred average electron densities are denoted in the figures. (a) $3 \times 10^{17} \mathrm{~W} / \mathrm{cm}^{2} ;(\mathrm{b}) 7 \times 10^{17} \mathrm{~W} / \mathrm{cm}^{2} ;(\mathrm{c}) 10^{18}$ $\mathrm{W} / \mathrm{cm}^{2}$; and (d) $2 \times 10^{18} \mathrm{~W} / \mathrm{cm}^{2}$.

sion was taking place $\left(n_{e}=6 \times 10^{22} \mathrm{~cm}^{-3}\right)$. Here, we simultaneously fit two lines ( $\mathrm{He}_{\beta}$ and $\mathrm{He}_{\gamma}$ lines) in order to fix the two free parameters, $n_{e}$ and $T_{i}$, from the line profiles. Although the error bar on $T_{i}$ evaluation remains large, this process gives an interesting information on the $T_{i}$ behavior. A rough estimate of the time-integrated electron temperature $T_{e}$ is obtained from a nonstationary calculation of the Ly ${ }_{\alpha} / \mathrm{He}_{\beta}$ line intensity ratio, assuming an optically thin plasma. The temperature is supposed to grow linearly up to a given value at which we extract the population, and the intensity line ratio calculated by the multicell time-dependent collisional radiative code TRANSPEC. ${ }^{46}$ Calculations were performed for a fixed ion density $n_{i}=5 \times 10^{21} \mathrm{~cm}^{-3}$, and for a temperature increasing from 0 to $T_{e}$ in $300 \mathrm{fs}$. For laser intensity around $3 \times 10^{18} \mathrm{~W} / \mathrm{cm}^{2}$, we infer $T_{e}=600 \mathrm{eV}$ from $\mathrm{Ly} / \mathrm{He}_{\beta}$ line ratio with such a calculation. Any changes in the conditions of the calculations $\left(n_{i}\right.$, nonlinear temperature ramp, opacity) should affect the $T_{e}$ evaluation. However, the large uncertainty in $T_{e}$ does not strongly affect the line profile, which is mainly sensitive to $n_{e}$ and $T_{i}$. Figure 3 presents the $\mathrm{He}_{\beta}$ [Fig. 3(a)] and $\mathrm{He}_{\gamma}$ [Fig. 3(b)] experimental line profiles (open dots) at $3 \times 10^{18} \mathrm{~W} / \mathrm{cm}^{2}$, and the best fits (solid lines) calculated for $T_{e}=600 \mathrm{eV}$. The inferred electron density and ion temperature are $n_{e}=5-7 \times 10^{22} \mathrm{~cm}^{-3}$ and $T_{i}=30-60 \mathrm{eV}$. While $\mathrm{He}_{\gamma}$ measurements and calculations in Fig. 3(b) agree quite well, it is more difficult to fit the $\mathrm{He}_{\beta}$ line profile [Fig. 3(a)]. In particular, no evidence of a central dip is observed in our data, in contrast to the calculated line shapes, also shown in Fig. 3(a). It was recently shown that ion dynamics could reduce the central dip $^{47}$ (in the case of a high- $Z$ emitter embedded in a hot low- $Z$ perturbing medium). However, we believe that, here, the temporal integration effects (variation of the emitting density and density gradients and eventual shifts in line position due to perturbing electrons) contribute to the filling in of the central dip and to the observed $\mathrm{He}_{\beta}$ profile.

The density at which the Li-like emission (dielectronic satellites) takes place, has been inferred from the $1 s 2 l 2 l^{\prime}-1 s^{2} 2 l$ line spectra. ${ }^{16}$ Our calculations ${ }^{16,17}$ show that this line spectrum could be strongly affected by non-steadystate population kinetics and also by the non-Maxwellian characters of the electron distribution function when pro- 


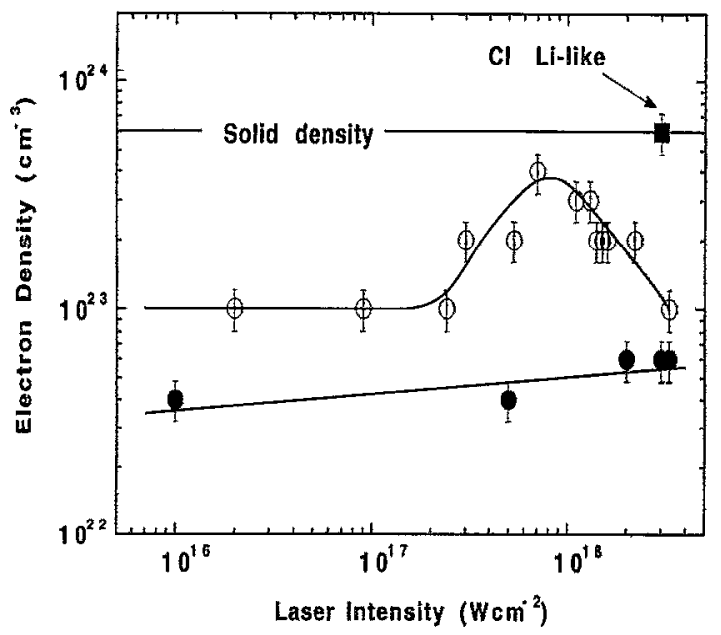

FIG. 5. Variation of the average electron density inferred from line profiles as a function of laser intensity. The full dots (He-like emission) and open dots ( $\mathrm{Li}$-like emission) have been obtained with Al targets. The square dot is obtained from $\mathrm{Cl}$ Li-like line shape (shown in Fig. 6).

duced at intermediate density $\left(n_{e}<5 \times 10^{22} \mathrm{~cm}^{-3}\right.$ for $\left.\mathrm{Al}\right)$. Our past experiments at lower laser intensity with a preformed plasma $^{11.48}$ and recent experiments with an 80 fs laser pulse ${ }^{18}$ confirm the importance of these effects. However, our previous results at $10^{16} \mathrm{~W} / \mathrm{cm}^{2}$ (400 fs green pulse irradiation with no prepulse) ${ }^{16.45}$ indicate that the time-integrated $1 s 2 l 2 l^{\prime}-1 s^{2} 2 l$ spectrum is radiating at an electron density of $10^{23} \mathrm{~cm}^{-3}$ for which the broadening is important and doubly excited level populations have reached the local thermodynamical equilibrium (LTE). Figure 4 shows $1 s 2 l 2 l^{\prime}-1 s^{2} 2 l$ line spectra measured for different laser intensities, with $\mathrm{Al}$ targets $3 \times 10^{17} \mathrm{~W} / \mathrm{cm}^{2}$ [Fig. 4(a)], $7 \times 10^{17} \mathrm{~W} / \mathrm{cm}^{2}$ [Fig. 4(b)], $10^{18} \mathrm{~W} / \mathrm{cm}^{2}$ [Fig. 4(c)] and $1.7 \times 10^{18} \mathrm{~W} / \mathrm{cm}^{2}$ [Fig. 4(d)]. The best calculation fits, assuming LTE populations among doubly excited levels, are also shown in Fig. 4. A very good agreement can be obtained between the measurement and calculation at lower intensity ${ }^{16}\left(I_{L}<10^{17} \mathrm{~W} / \mathrm{cm}^{2}\right)$. However, at higher intensity it is more difficult to fit correctly the short-wavelength side of the spectrum and the intensity of the $q, r$ peak is higher in the experiments. A similar effect was recently observed in experiments performed with shorter pulses ${ }^{18}$ and the $q, r$ satellite intensity problem was attributed to some temporal integration effects. A more quantitative understanding of these spectra would require a fully timedependent calculation of the plasma hydrodynamics, population kinetics, and line shape calculations.

Figure 5 presents the variation of the density inferred from He-like and Li-like Al line profiles as a function of the laser intensity. The results at $10^{16} \mathrm{~W} / \mathrm{cm}^{2}$, obtained with a lens and in normal incidence, are from our previous experiments. ${ }^{16,45}$ The other points have been obtained with the conditions described in Sec. II. The density for He-like emission is constant with the laser intensity, and the inferred ion temperature is always smaller than the electron temperature $\left(T_{e}=200 \mathrm{eV}, T_{i}=5-30 \mathrm{eV}\right.$ at $10^{16} \mathrm{~W} / \mathrm{cm}^{2}, T_{e}=300 \mathrm{eV}$, $T_{i}=20-100 \mathrm{eV}$ at $5 \times 10^{17} \mathrm{~W} / \mathrm{cm}^{2}$, and $T_{e}=600 \mathrm{eV}$, $T_{i}=30-60 \mathrm{eV}$ at $\left.2-3 \times 10^{18} \mathrm{~W} / \mathrm{cm}^{2}\right)$. The density for Li-like emission has a different behavior; the Li-like density is con- stant at $10^{23} \mathrm{~cm}^{-3}$ for the lowest laser intensities $I_{L}$, but increases when $I_{L}>3 \times 10^{17} \mathrm{~W} / \mathrm{cm}^{2}$ up to some maximum value of $4 \times 10^{23} \mathrm{~cm}^{-3}$, which is close to the solid density of a Li-like Al plasma $\left(\rho=\rho_{0}, Z^{*}=10\right.$, and $\left.n_{e}=6 \times 10^{23} \mathrm{~cm}^{-3}\right)$. For $I_{L}$ above $10^{18} \mathrm{~W} / \mathrm{cm}^{2}$, the Li-like density dramatically decreases.

These results suggest that the radiative pressure plays a very important role at these laser intensities. Indeed, at low laser intensity the gradient scale length is very short, and energy deposition is realized at near solid density. In the absence of any ponderomotive pressure, when the intensity increases, the gradient scale length increases while the density $n_{e}$ at which energy deposition takes place decreases ${ }^{49}$ $\left(n_{e}\right.$ scales roughly as $I^{4 / 5}$ ). Thus, the densities of the emitting He-like and $L i$-like radiations are expected to decrease when $I_{L}$ increases. However, at higher intensities the radiation pressure could eventually balance the thermal pressure, maintaining a very steep electron density gradient during the energy deposition, and producing a deep penetration of the thermal wave in the solid, thus causing the emission to be produced at near solid density.

The behavior of $\mathrm{Al} \mathrm{Li-like} \mathrm{density} \mathrm{at} \mathrm{intensity} \mathrm{larger} \mathrm{than}$ $10^{18} \mathrm{~W} / \mathrm{cm}^{2}$ is interesting. Recent calculations indicate that short pulse emission, and thus solid density plasma, can be obtained if the plasma heating is in some optimum range set by target materials. ${ }^{50}$ Two alternative scenarios can explain the lower emission density of the Li-like Al K-shell emission at intensities above $10^{18} \mathrm{~W} / \mathrm{cm}^{2}$ : (a) the prepulse effect could be larger than estimated, so that the pulse would interact with preformed, lower-density plasma; (b) the plasma is overheated, that is, after the laser pulse, as it expands and cools, it is still sufficiently hot to emit Li-like K-shell x-ray lines. Both scenarios are also compatible with the observation of strong $L y_{\alpha}$ emission when $I_{L}>10^{18} \mathrm{~W} / \mathrm{cm}^{2}$, scaling as $I_{L}^{2}$, indicating a high electron temperature. To decide between the two scenarios, we observed Li-like $\mathrm{Cl}$ lines $\left(\mathrm{Cl}^{14+}\right)$ from a sodium chloride $(\mathrm{NaCl})$ target irradiated at $3 \times 10^{18} \mathrm{~W} / \mathrm{cm}^{2}$. The choice of $\mathrm{NaCl}$ was dictated by (i) the possibility to measure the density of emission from higher atomic number material that are matched more appropriately to high temperature; (ii) the fact that in $\mathrm{Li}$-like $\mathrm{Cl}$ and $\mathrm{Li}$-like $\mathrm{Al}$ solid density plasmas (using solid $\mathrm{NaCl}$ and $\mathrm{Al}$ targets) the electron densities are the same $\left(6 \times 10^{23} \mathrm{~cm}^{-3}\right)$. Figure 6 presents the $1 s 2 l 2 l^{\prime}-1 s^{2} 2 l \mathrm{Cl}$ line spectrum measured at $3 \times 10^{18}$ $\mathrm{W} / \mathrm{cm}^{2}$. The best fit between experimental and calculation results indicates that this emission is produced at around $6 \times 10^{23} \mathrm{~cm}^{-3}$ which is the Li-like solid density (Fig. 5). Furthermore, no thermal He-like and Li-like emissions ( $\mathrm{keV}$ range) was observed at $3 \times 10^{18} \mathrm{~W} / \mathrm{cm}^{2}$ with a Ti target $(Z$ $=22$ ). These results (i) demonstrate that there is no prepulse in our experiments, even at the highest intensities; (ii) highlight a very important aspect for the generation of emitting solid density plasma: it is essential to match the emitting target to $T_{e}$ for a given isoelectronic sequence. It is also interesting to note that the $\mathrm{Cl} \mathrm{Li}$-like emission should be very short, because it is produced at a very large density. 


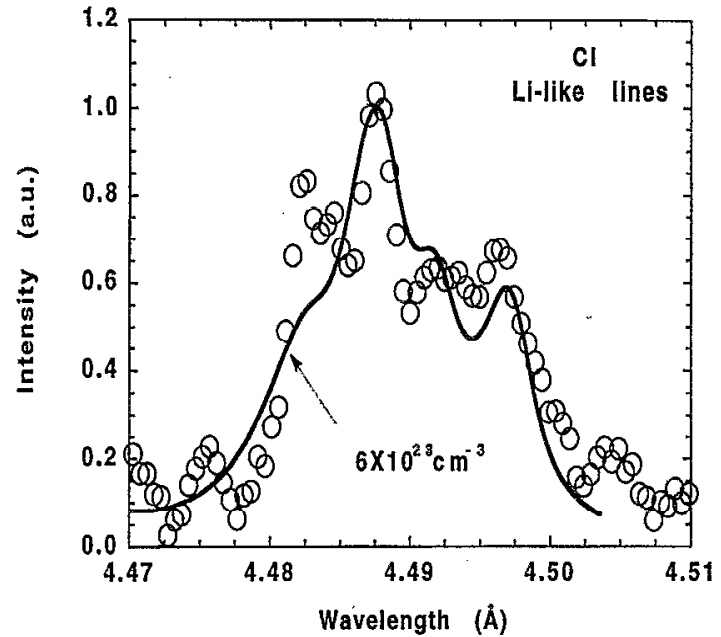

FIG. 6. The profile of $\mathrm{Li}$-like $\mathrm{Cl}$ lines (open dots). The $\mathrm{NaCl}$ target is irradiated by a $3 \times 10^{18} \mathrm{~W} / \mathrm{cm}^{2}$ laser pulse. The best profile fitting (solid line) indicates the emitting density is around $6 \times 10^{23} \mathrm{~cm}^{-3}$, which is solid density for $\mathrm{Li}$-like $\mathrm{Cl}$ of $\mathrm{NaCl}$

\section{THERMAL TRANSPORT}

Additional understanding of the high-intensity regime for $\mathrm{Al}$ targets, can be obtained from thermal transport measurements. Thermal conduction may drive the density at which Li-like emission is produced. During the laser pulse, when radiation pressure is effective, thermal conduction can also play a very important role in plasma cooling, and will eventually limit the temperature. However, at these high intensities the plasma expansion is another important cooling mechanism that cannot be neglected, particularly when the plasma is overdriven.

We use multilayer targets composed of polished Si substrate coated with $0.01-5 \mu \mathrm{m} \mathrm{Al} \mathrm{layers,} \mathrm{and} \mathrm{we} \mathrm{follow} \mathrm{the}$ intensity of $\mathrm{Si}$ and $\mathrm{Al}$ lines as a function of the Al thickness. Figure 7 presents a spectrum $(6.2-7.2 \AA)$ recorded with a $\mathrm{Si}$ target coated with $1000 \AA \mathrm{Al}$ irradiated at $3.4 \times 10^{18} \mathrm{~W} / \mathrm{cm}^{2}$.

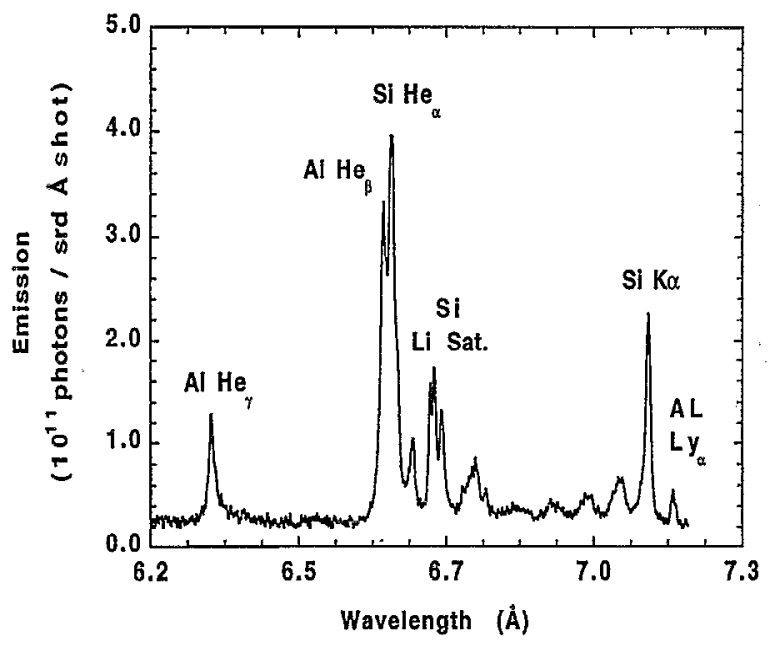

FIG. 7. Spectrum in the $6.2-7.2 \AA$ range recorded with a $S i$ target coated with $1000 \AA \mathrm{Al}$ irradiated at $3.4 \times 10^{18} \mathrm{~W} / \mathrm{cm}^{2}$. The different lines are indicated in the figure. The $\mathrm{Si} / \mathrm{He}_{\alpha}$ will disappear when the Al layer is $3000 \AA$ thick or above at this laser intensity.

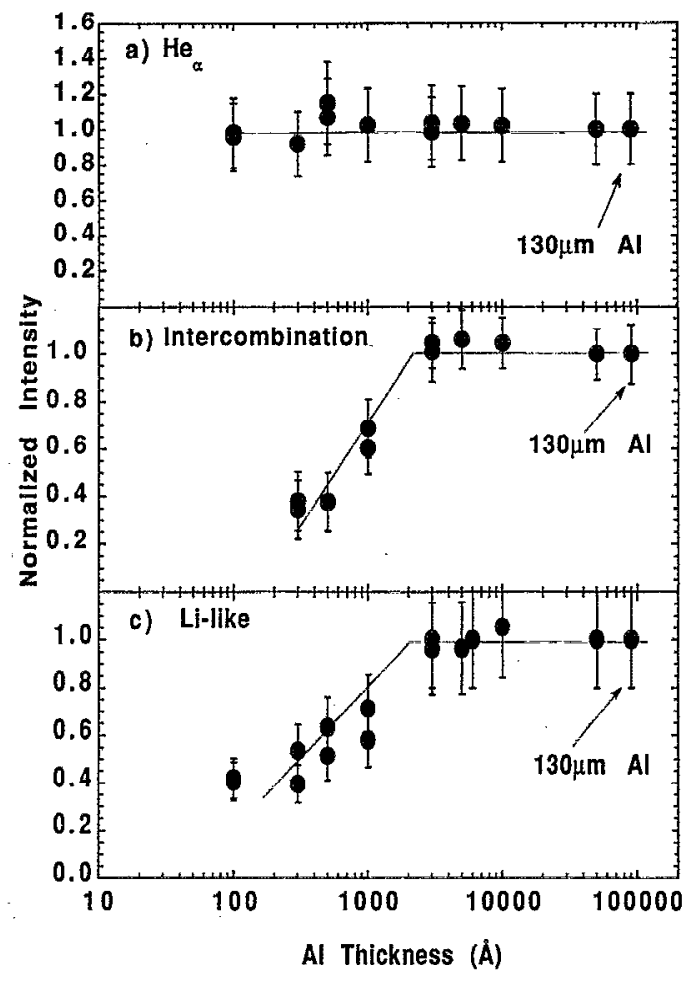

FIG. 8. The variation of Al line intensity as a function of the Al layer thickness in multilayer target experiment at laser intensities of $2 \times 10^{18}$ $\mathrm{W} / \mathrm{cm}^{2}$. The penetration depth of thermal energy (temperature around 600 $\mathrm{eV}$ ) is about $2000 \AA$. (a) $\mathrm{He}_{\alpha}$ line, (b) intercombination line, and (c) Li-like lines.

We observe $\mathrm{Al}$ lines $\left(\mathrm{He}_{\beta}\right.$ and $\mathrm{He}_{\gamma}$ and $\left.\mathrm{Ly}_{\alpha}\right)$ and $\mathrm{Si} \mathrm{He}_{\alpha}$, Li-like, and $\mathrm{K}_{\alpha}$ lines. As the thickness of the Al layer is increased, the Al line intensity increases up to a saturation level, which is the intensity obtained with a thick $(130 \mu \mathrm{m})$ target. The depth at which the saturation occurs is usually considered as a measure of the penetration of the thermal front. At $2 \times 10^{18} \mathrm{~W} / \mathrm{cm}^{2}$, the very quick saturation of $\mathrm{AlHc}_{\alpha}$ line seems to indicate a limited penetration $(<100 \AA)$ of the higher temperature thermal front [Fig. 8(a)]. However, the intercombination line [Fig. 8(b)] and the Li-like satellites emission [Fig. 8(c)] have a much larger penetration depth than resonance line. These lines (intercombination and satellites) give a thermal penetration depth of around $2000 \AA$. Thus, the heating of the Al target by conduction occurs within the $2000 \AA$ layer, where the plasma density remains near solid and the temperature is around $600 \mathrm{eV}$. At such high temperature the He-like ions population should dominate, but due to the rapid dielectronic recombination and ionization delay, the Li-like population is large within the hot plasma. Furthermore, the different behaviors of the resonance and intercombination lines seems to indicate that the effects of autoabsorption are very strong and limit the observed emission depth of $\mathrm{He}_{\alpha}$ line. The same situation is observed for $\mathrm{Ly}_{\alpha}$ line.

This penetration of thermal energy is in qualitative agreement with simple scaling laws, representing the penetration of a heat wave by classical electron thermal conduction in a constant solid density plasma (no hydrodynamic expansion and assuming a given energy flux at one end). ${ }^{51}$ 


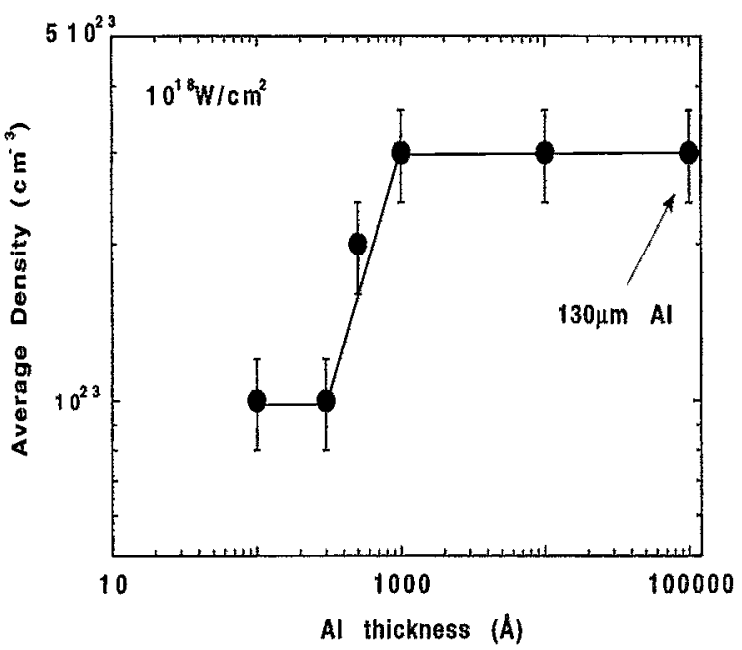

FIG. 9. The average density of Li-like Al lines as a function of Al layer thickness at a laser intensity of $10^{38} \mathrm{~W} / \mathrm{cm}^{2}$, deduced from line profiles similar to that shown in Fig. 5.

During the laser pulse the surface temperature $T_{0}$ and the heat front penetration depth $X_{0}$ are given by the following expressions: $^{52}$

$$
\begin{aligned}
& T_{0}=3.2 \times 10^{-7} I_{a}^{1 / 9} \tau^{2 / 9}, \\
& X_{0}=1.8 \times 10^{-8} I_{a}^{5 / 9} \tau^{7 / 9},
\end{aligned}
$$

where $T_{0}$ is in hundreds of $\mathrm{eV}, X_{0}$ in $\mathrm{cm}, I_{a}$ is the absorbed intensity (in $\mathrm{erg} / \mathrm{cm}^{2} \mathrm{~s}$ ), and $\tau$ is the laser duration (in s). Assuming $1 \%$ absorption $\left(I_{u}=10^{16} \mathrm{~W} / \mathrm{cm}^{2}\right)$ and $\tau=300 \mathrm{fs}$, we obtain $T_{0}=880 \mathrm{eV}$, in relative agreement with the $T_{e}$ value inferred from the time-dependent $\mathrm{Ly}_{\alpha} / \mathrm{He}_{\beta}$ ratio, and $X_{0}=1900 \AA$, consistent with the thermal penetration deduced from the intercombination line and Li-like lines [Figs. 8(b) and $8(\mathrm{c})]$. Recent kinetic simulations of this regime indicate an absorption of around $1 \%$, an electron temperature $T_{e}$ around $1 \mathrm{keV}$, and a thermal penetration of $2500 \AA^{53}$

However, the hot surface layer will decompress, during the cooling after the laser pulse, due to some hydrodynamics, leading to a relatively lower time-integrated density at which He-like emission takes place. The same part of Li-like emission is also produced in this decompressing plasma but is due to the very large Li-like production thickness at solid density (larger penetration of the lower-temperature front) the density at which total Li-like emission takes place remains close to solid density (Fig. 5). This is illustrated by Fig. 9, which presents the average Li-like density (deduced from the shape of the Li-like spectrum as previously described) as a function of the $\mathrm{Al}$ thickness at $10^{18} \mathrm{~W} / \mathrm{cm}^{2}$.

Thus, at very high intensity, the very hot surface layer of the Al target will cool on a time scale larger than the pulse duration, leading to $\mathrm{x}$-ray emission during the plasma decompression. A quantitative understanding of these processes would require hydrodynamics or kinetics calculations coupled to atomic physics modeling. Such simulations are presently in progress. ${ }^{53}$

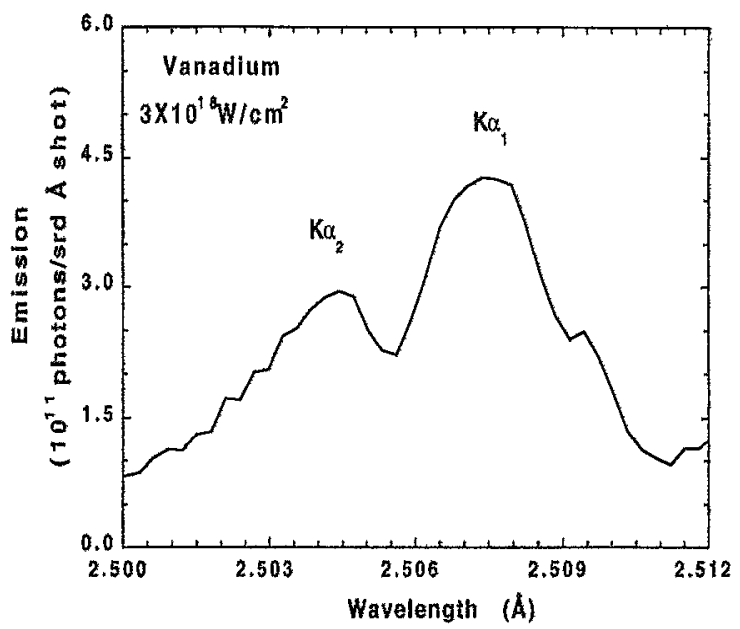

FIG. 10. The cold $\mathrm{K}_{\alpha}$ spectrum of vanadium obtained at laser intensity of $3 \times 10^{18}$ W/em ${ }^{2}$ lobtained with Von Hamos crystal spectrometer operated at second diffraction order).

\section{SUPRATHERMAL TRANSPORT}

Comparison between thermal transport measurements and simple analytic estimates for the heat propagation, as previously discussed, require the use of a very low absorption value (consistent with the results of a more elaborate calculation performed at various laser intensities). ${ }^{53}$ However, recent experiments with sub-ps lasers at intensities around $10^{17} \mathrm{~W} / \mathrm{cm}^{2}$ suggest absorption is between $10 \%-30 \%$ of the laser energy and also that an important fraction of the laser energy is carried by hot electrons. ${ }^{54.55}$ Here we used $\mathrm{K}_{\alpha}$ yield measurements in order to obtain information on the hot electron energy content and deposition profile. The $\mathrm{K}_{\alpha}$ emission is recorded with the Von Hamos crystal spectrometer and with PIN diodes (with magnets in front to avoid hot electron fluorescence). Scandium $(50 \mu \mathrm{m})$ and titanium $(25$ $\mu \mathrm{m})$ foils are used as Ross filters with the diodes to obtain the $\mathrm{K}_{\alpha}$ emission of a Vanadium target. ${ }^{56}$ The difference between the signals obtained with the Sc and Ti filters is predominantly due to $\mathrm{V} \mathrm{K}_{\alpha}$ emission, the continuum emission in the Ross filter window being a small fraction of the total signal (as verified with various $\mathrm{Z}$ targets). The $\mathrm{K}_{\alpha}$ yield measured with the diodes can be used to calibrate the crystal spectrometer. the $\mathrm{V} \mathrm{K}_{\alpha}$ spectrum measured at $3 \times 10^{18} \mathrm{~W} / \mathrm{cm}^{2}$ with the crystal spectrometer (second diffraction order) appears in Fig. 10. We observed the $\mathrm{K}_{\alpha 1}$ and $\mathrm{K}_{\alpha 2}$ doublet (transitions from the $K$ shell to respectively the $L_{3}$ and $L_{2}$ levels), with the expected relative intensities ${ }^{57}$ (the $\mathrm{K}_{\alpha 22} / \mathrm{K}_{\alpha 1}$ intensity ratio should be 0.5 ). In these conditions the $K_{\alpha}$ yield measured with the Ross diodes is $2 \times 10^{-3} \mathrm{~mJ} / \mathrm{srd}$, for $600 \mathrm{~mJ}$ laser energy, corresponding to a conversion efficiency of $3.3 \times 10^{-4} \%$ srd. The energy in fast electrons is calculated from the energy in $\mathrm{K}_{c x}$ emission by using a conversion efficiency $R\left(T_{h}\right)$ deduced from the $\mathrm{K}_{\alpha}$ yield per electron ${ }^{56}$ (which was measured for monoenergetic electrons incident on thick $\operatorname{target}^{58}$ ). For these calculations we assume that hot electrons (spatially integrated) angular distribution is semiisotropic and that the energy distribution has the following form: 


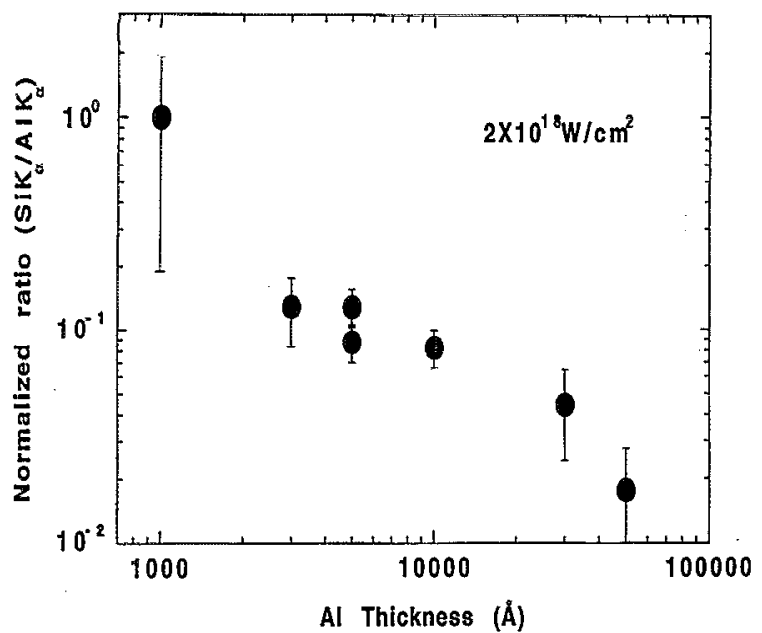

FIG. 11. The line intensity ratio of $\mathrm{Si} \mathrm{K}_{\alpha}$ and $\mathrm{Al} \mathrm{K}_{\alpha}$ as a function of Al layer thickness at $2 \times 10^{18} \mathrm{~W} / \mathrm{cm}^{2}$, from which we infer a hot electron temperature of $25 \mathrm{keV}$. The absorption of $\mathrm{Si} \mathrm{K}_{\alpha}$ emission due to the Al layer is taken into account.

$$
f(E)=A E^{1 / 2} \exp \left(-E / k T_{h}\right),
$$

where $k T_{h}$ is the hot electron temperature. The hot electron temperature is deduced from the variations of the $\mathrm{Al}$ and $\mathrm{Si}$ $\mathrm{K}_{\alpha}$ intensities as a function of $\mathrm{Al}$ thickness (Fig. 11). From these, and using previously published calculation for hot electron penetration in $\mathrm{Al}^{59}$ we found that at $2 \times 10^{18} \mathrm{~W} / \mathrm{cm}^{2}$, $k T_{h}$ is about $25 \mathrm{keV}$. For vanadium, $R\left(T_{h}\right)$ is relatively independent of $T_{h}$ when $10 \mathrm{keV}<k T_{h}<50 \mathrm{keV}$ and is about $9 \times 10^{-4}$. Thus, the energy deposited by the incident hot electrons is about $5 \%$ of the laser energy at intensity of $3 \times 10^{18}$ $\mathrm{W} / \mathrm{cm}^{2}$. At lower intensity $\left(10^{16} \mathrm{~W} / \mathrm{cm}^{2}\right)$ the energy in hot electrons that produce $\mathrm{K}_{\alpha}$ emission is very small and is about $0.06 \%$ of the laser energy. ${ }^{45}$

Then at very high intensity (and in $S$ polarization), less than $10 \%$ of the laser energy is coupled to the target. A small percentage is due to classical collisional absorption and induces a heating of a thin layer of material (2000 $\AA$ ). About $5 \%$ is due to long range hot electrons, with a $25 \mathrm{keV}$ hot electron temperature, which penetrate deeply in the target (3 $\mu \mathrm{m})$.

\section{ULTRAFAST X-RAY SOURCES}

The combination of a high laser intensity and a high plasma density should allow the generation of a high brightness ultrafast source of short-wavelength radiation. ${ }^{11}$ The photon yield (line emission) increases with the laser intensity, as shown in Fig. 12. The photon yields for $\mathrm{He}_{\alpha}$ [Fig. 12(a)], Li-like $\left[a-d\right.$ inner shell satellites, Fig. 12(b)] and $\mathrm{K}_{\alpha}$ emissions [Fig. 12(c)] from Al scale respectively as $I_{L}^{1.5}, I_{L}^{1.5}$, and $I_{L}^{1.0}$ for laser intensity, $10^{17} \mathrm{~W} / \mathrm{cm}^{2}<I_{L}<4 \times 10^{18} \mathrm{~W} / \mathrm{cm}^{2}$. When $I_{L}>10^{18} \mathrm{~W} / \mathrm{cm}^{2}$, the $\mathrm{Ly}_{\alpha}$ line emission increases sharply as $I_{L}^{2}$. The scaling obtained for the $\mathrm{He}_{\alpha}$ line emission is different from the scaling measured at lower laser intensities $\left(I_{L}^{4.3}\right.$ in the $10^{14} \mathrm{~W} / \mathrm{cm}^{2}$ range ${ }^{15}$ and $I_{L}^{2.2}$ in the $10^{16}$ $\mathrm{W} / \mathrm{cm}^{2}$ range ${ }^{60}$ ), but is similar to the dependence recently reported in some experiments at similar laser intensities. ${ }^{61}$

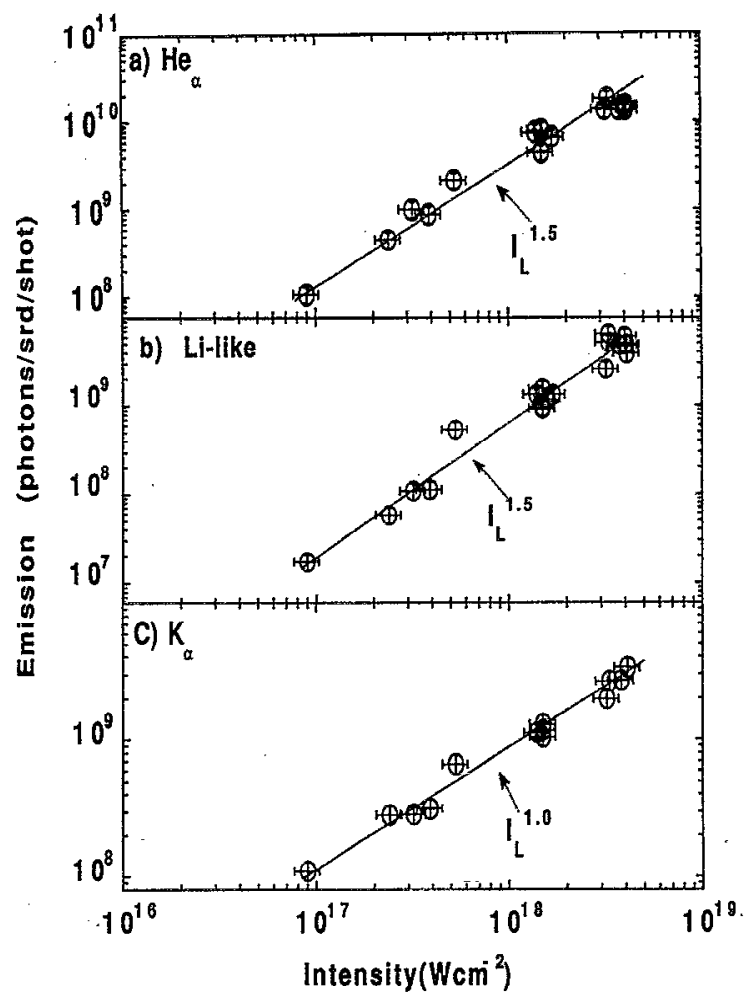

FIG. 12. The photon yièlds of Al lines as a function of laser intensity. (a) $\mathrm{He}_{\alpha}$ line, (b) Li-like lines ( $a-d$ inner shell satellites), and (c) $\mathrm{K}_{\alpha}$ line.

This indicates that the slope of the line yield power law decreases with increasing laser intensity for $I_{L}>10^{16} \mathrm{~W} / \mathrm{cm}^{2}$.

By choosing suitable target materials, one could get very bright $\mathrm{x}$-ray radiation for certain short wavelengths. Around $2.5 \times 10^{10}$ photons are measured at $4.5 \AA$ in a $0.4 \%$ bandwidth with $3 d-5 f$ unresolved transition array (UTA) emissions from the Ta target (Fig. 13) and with $3 d-4 f$ transitions (the Ta target) up to $2 \times 10^{11}$ photons are obtained at around 6 $\AA$ in a $3 \%$ bandwidth. At $3 \times 10^{18} \mathrm{~W} / \mathrm{cm}^{2}, \mathrm{~K}_{\alpha}$ emission allows

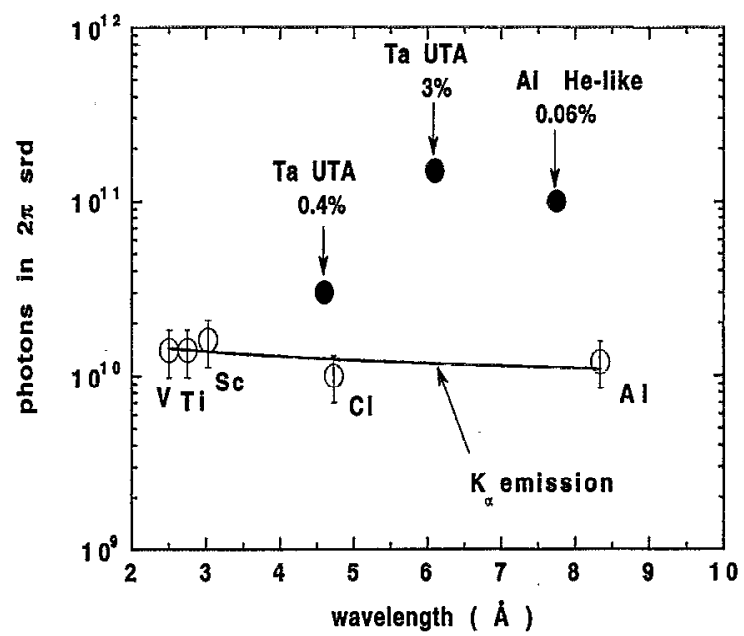

FIG. 13. Short-wavelength $\mathrm{x}$-ray yields at laser intensity of $3 \times 10^{18} \mathrm{~W} / \mathrm{cm}^{2}$. The $\mathrm{K}_{\alpha}$ photon yield ( $6 \mathrm{~mA}$ bandwidth) appears as a function of atomic number. The total emission photons for Ta $3 d-4 f$ UTA emissions (3\% bandwidth), Ta $3 d-4 f$ UTA emissions ( $0.4 \%$ bandwidth) and for Al He-like $(0.06 \%$ bandwidth) are also plotted. 
the obtention of around $10^{10}$ photons in $2 \pi$ srd (Fig. 13) down to very short wavelength (3-9 $\AA$ range).

The $\mathrm{x}$-ray yield increases as the laser intensity increases. However, it is worthy to note that there are some optimum conditions for the obtention of high-density plasma, since the shortest $\mathrm{x}$-ray pulse is produced for the highest emitting plasma density. This highlights a very important and novel point, which is that there are some optimal windows for the production of simultaneously the shortest and brightest $\mathrm{x}$-ray pulse for a given wavelength. For instance, taking into account the results described in Sec. IV, the simultaneously brightest and shortest $\mathrm{Li}$-like lines of the $\mathrm{Al}$ target should be produced at laser intensity of $7-9 \times 10^{17} \mathrm{~W} / \mathrm{cm}^{2}$.

\section{CONCLUSION}

The generation of solid density emitting plasma can be achieved with subpicosecond high contrast laser pulses at an intensity of $10^{18}-10^{19} \mathrm{~W} / \mathrm{cm}^{2}$ by using the radiation pressure to balance the dense slab thermal pressure during the laser heating and maintain a very deep thermal front penetration into the solid. Our experiments show that there is an optimum condition to produce emission at solid density. At very high laser intensity (larger than $10^{18} \mathrm{~W} / \mathrm{cm}^{2}$ for $\mathrm{Al}$ ), the electron temperature may be very high resulting in an overdriven Al plasma. Thus, for a given pulse duration and intensity it is essential to match the target to the electron temperature to generate emitting plasma at solid density. The energy balance, deduced from thermal and suprathermal penetration depths, and from $\mathrm{K}_{\alpha}$ yield measurements, indicates that about $6 \%$ of laser energy is coupled to the target at $2 \times 10^{18}$ W/ $/ \mathrm{cm}^{2}\left(1 \% E_{L}\right.$ in thermal electrons at a temperature of 600 $\mathrm{eV}$ and $5 \% E_{L}$ in hot electrons with a hot temperature $T_{h}=25 \mathrm{keV}$ ). Interesting conversion efficiencies are obtained in various line emissions in these conditions. These results also highlight a very important and novel point, which is that there is some optimal window for the production of simultaneously the shortest and brightest $\mathrm{x}$-ray pulse for a given wavelength (about $10^{18} \mathrm{~W} / \mathrm{cm}^{2}$ for Li-like Al emission). The $\mathrm{x}$-ray yield (and also the energy fraction in hot electrons) increases with the driven laser intensity, but above some laser intensity the plasma is overdriven and the thermal radiation is produced at a lower-density region, and there is significant increase of the $\mathrm{x}$-ray pulse duration. At laser intensity around a few times $10^{18} \mathrm{~W} / \mathrm{cm}^{2}$, by using moderate- $Z$ targets (Ti, for example) and high- $Z$ targets (Ta, for example) we obtained up to $10^{10}$ photons $/ 2 \pi$ srd per shot in cold $\mathrm{K}_{\alpha}$ emission (Ti, narrow bandwidth) and $2 \times 10^{11}$ photons $/ 2 \pi$ srd per shot in unresolved transition array $(\mathrm{Ta}$, larger bandwidth), which is very encouraging for the application of ultrafast bright $\mathrm{x}$-ray sources.

\section{ACKNOWLEDGMENTS}

The authors would like to thank H. Pépin and D. Umstadter for many helpful discussions, C. Y. Coté for help in data analysis, C. Y. Chien for laser operation, and C. Sirois and F. Poitras for technical support.

This work was supported by the Natural Sciences and Engineering Research Council of Canada, le Fonds pour la
Formation de Chercheurs et l'Aide à la Recherche and Ministere de l'éducation du Québec. One of the authors $(\mathrm{Z}$. Jiang) would like to acknowledge the support from the Chinese Academy of Sciences.

'J. D. Lindl, E. M. Campbell, and R. L. McCrory, Phys. Today 45, 32 (1992); J. Duderstadt and G. Moses, Intertial Confinement Fusion (Wiley, New York. 1982).

${ }^{2}$ W. Priedhorsky. D. Lier. R. Day, and D. Gerke, Phys. Rev. Lett. 47, 1661 (1981).

${ }^{3}$ B. Yaakoki, J. Delettrez, C. M. Goldman, R. L. McCrory, W. Seka, and J. M. Soures. Opt. Commun. 41, 355 (1982).

${ }^{4}$ G. Mourou and D. Umstadter, Phys. Fluids B 4, 2315 (1992).

${ }^{5}$ M. D. Perry and G. Mourou, Science 264, 917 (1994).

${ }^{6}$ D. Strickland and G. Mourou, Opt. Commun, 56, 219 (1985); P. Maine, D. Strickland. P. Bado, M. Perot, and G. Mourou, IEEE J. Quantum Electron. QE-24, 398 (1988).

${ }^{7}$ M. Murnane, H. C. Kapteyn, and R. W. Falcone, Phys. Rev. Lett. 62, 155 (1989).

${ }^{8}$ H. Milchberg. R. R. Freeman, S. C. Davey, and R. M. More, Phys. Rev. Lett, 61. 2364 (1988).

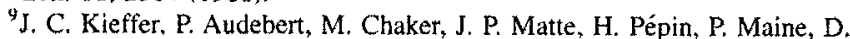
Meyerhofer, J. Deletrez, D. Strickland, P. Bado, and G. Mourou, Phys. Rev, Lett. 62. 760 (1989).

${ }^{16}$ J. P. Babuel-Peyrissac, C. Fauquignon, and F. Floux, Phys. Lett. A 30, 290 (1969); A. Caruso and R. Gratton, Plasma Phys. 11, 839 (1969).

"J. C. Kieffer, M. Chaker, J. P. Matte, H. Pepin, C. Y. Coté, Y, Beaudoin, T. W. Johnston. C. Y. Chien, S. Coe, G. Mourou, and O. Pcyrussc, Phys. Fluids B 5, 2676 (1993).

${ }^{12}$ B. Soom. H. Chen, Y. Fisher, and D. D. Meyerhofer, J. Appl. Phys. 74, 5372 (1993).

${ }^{13}$ G. A. Kyrala. R. D. Fulton, E. K. Waklin, L. A. Jones, G. T. Shappert, J. A. Cobble, and A. J. Taylor, Appl. Phys. Lett. 60, 2195 (1992).

${ }^{14} \mathrm{P}$. Audebert, J. P. Geindre, J. C. Gauthier. A. Mysyrowicz, P. Chambaret, and A. Antonetti. Europhys. Lett. 19, 189 (1992).

${ }^{15}$ D. G. Stearns, O. L. Landen, E. M. Campbell, and J. H. Scofield, Phys. Rev. A 37, 1684 (1988).

${ }^{16}$ O. Peyrusse, J. C. Kieffer, C. Y. Coté, and M. Chaker, J. Phys. B 26, L5U (1993).

17J. P. Matte, J. C. Kieffer, S. Ethier, M. Chaker, and O. Peyrusse, Phys. Rev. Lett. 72, 1208 (1994).

${ }^{18}$ R. Mancini. P. Audebert. J. P. Geindre. A. Rousse, F. Falies, J. C. Gauthier, A. Mysyrowicz. J. P. Chambaret, and A. Antonetti, J. Phys. B 27, 1671 (1994): P. Audebert, J. P. Geindre, A. Rousse, F. Falies, J. C. Gauthier, A. Mysyrowicz. G. Grillon, and A. Antonetti. J. Phys. B 27, 3303 (1994).

${ }^{19} \mathrm{~W}$. L. Kruer in The Physics of Laser Plasma Interaction (AddisonWesley, Reading, MA. 1988), p. 60.

${ }^{20} \mathrm{X}$. Liu and D. Umstadter, Phys. Rev. Lett. 69, 1935 (1992).

${ }^{21}$ S. C. Wilks, W. L. Kruer, M. Tabak. and A. B. Langdon, Phys. Rev. Lett. 69, $1383(1992)$.

${ }^{22}$ M. P. Kalashnikov, R. V. Nickles, Th. Schlegel, M. Schnuerer, F. Billhardt, I. Will. W. Scandner, and N. N. Demchenko, Phys. Rev. Lett. 73, 260 (1994).

${ }^{23}$ M. Takak, J. Hammer, M. E. Clinsky, W. L. Kruer, S. C. Wilks, J. Woodworth, E. M. Campbell, M, D. Perry, and R. J. Mason, Phys. Plasmas 1, 1626 (1994).

${ }^{24}$ H. Hamster, A. Sullivan, S. Gordon, W. White, and R. W. Falcone, Phys. Rev. Lett. 71. 2725 (1993).

${ }^{25}$ A. R. Bell, F, N. Beg, Z. Chang. A. E. Danger. C. N. Danson, C. B. Edwards, A. P. Fews, M. H. R. Hutchinson, S. Luan, P. Lee, P. A. Norreys, R. A. Smith, P. F. Taday, and F. Zhou, Phys. Rev. B 48, 2087 (1993).

${ }^{26}$ C. B. Darrow, C. Coverdale, M. D. Perry, W. B. Mori, C. Clayton, K. Marxh, and C. Joshí, Phys. Rev. Lett. 69, 442 (1992).

${ }^{27}$ H. A. Baldis, D. M. Villeneuve, B. La Fantaine, G. D. Enright, C. Labaune, S. Baton, Ph. Mounaix, D. Pesme, M. Casanova, and W. Rozmus, Phys, Fluids B 5, 3319 (1993).

${ }^{28}$ J. C. Kieffer, J. P. Matte, H. Pépin, M. Chaker, Y. Beaudoin, C. Y. Chien, S. Coe, G. Mourou, and J. Dubau, Phys. Rev. Lett. 68, 480 (1992); J. C. Kieffer, J. P. Matte, H. Pépin, M. Chaker, Y. Beaudoin. C. Y. Chien, S. Coe, G. Mourou, J, Dubau, and M. K. Inal, Phys. Rev. E 48, 4648 (1993).

${ }^{20}$ F. J. Rogers and C. A. Iglesias, Science 263, 50 (1994).

${ }^{301}$ M. A. Berkovsky, Yu. K. Kurilenkov, and H. M. Milchberg, Phys. Fluids B 
4, 2423 (1992); H. M. Milchberg, R. R. Freman, S. C. Davey, and R. M. More, Phys. Rev. Lett. 61, 2364 (1988).

${ }^{31}$ C. Bauche-Amoult, J. Bauche, E. Luc-Koenig, J. F. Wyart, R. M. More, C. Chenais-Popovics, J. C. Gauthier, J. P. Geindre, and N. Tragin, Phys. Rev. A 39, 1053 (1993).

${ }^{32}$ E. Leboucher-Dalimier, A. Poquerusse, and P. Angelo, Phys. Rev. E 47, 1467 (1993).

${ }^{33}$ H. C. Kapteyn, Appl. Opt. 31, 4931 (1992).

${ }^{34}$ J. P. Bergsma, M. H. Coladonato, P. M. Edelsten, J. D. Khan, K. R. Wilson, and D. R. Fredkin, J. Chem. Phys. 84, 6151 (1986).

${ }^{35}$ K. Herrlin, G. Svahn, C. Olsson, H. Petterson, C. Tillman, A. Persson, S. Svanberg, Radiology 189, 65 (1993).

${ }^{36}$ Y. Beaudoin, C. Y. Chien, J. S. Coe, J. L. Tapie, and G. Mourou, Opt. Lett. 17, 865 (1992).

${ }^{37}$ C. Y. Chien, Ph.D thesis, University of Michigan, 1994.

${ }^{38}$ B. Henke, F. Fujiwara, M. Tester, C. Dittmore, and M. Palmer, J. Opt. Soc. Am. B 1, 528 (1984).

${ }^{39} \mathrm{G}$. Senemaud, J. Phys. Paris 30, 811 (1969).

${ }^{40} \mathrm{R}$. Hall, M. Lewis, B. Leigh, and K. Evans, X-ray Spectrom. 8, 19 (1979).

${ }^{41}$ M. Baranger, Phys. Rev. 111, 481,494 (1958); 112, 855 (1958); A. Kolb and H. Griem, 111, 514 (1958).

${ }^{42}$ D. Gilles, in Spectral Line Shapes, edited by L. Frommhold and J. W. Keto (American Institute of Physics, New York, 1990), Vol. 6, p. 48.

${ }^{43}$ F. Perrot, Phys. Rev. A 26, 1035 (1982); and (private communication, 1992).

${ }^{44}$ R. J. Tighe and C. F. Hooper, Jr., Phys. Rev. A 15, 1773 (1977); 17, 410 (1978).

${ }^{45}$ J. C. Kieffer, M. Chaker, J. P. Matte, C. Y. Coté, Y. Beaudoin, Z. Jiang, C. Y. Chien, S. Coe, G. Mourou, O. Peyrusse, and D. Gilles, Short Pulse High Intensity Lasers and Applications II (Society of Photo-optical Instrumentation Engineers, Bellingham, WA, 1993), Vol. 186, p. 127; C. Y. Chien, J. S. Coe, G. Mourou, J. C. Kieffer, M. Chaker, Y. Beaudoin, O. Peyrusse, and D. Gilles, Opt. Lett. 18, 1535 (1993).
${ }^{46}$ O. Peyrusse, Phys. Fluids B 4, 2007 (1992).

${ }^{47}$ C. J. Keane, B. A. Hammel, D. R. Kania, J. D. Kilkenny, R. W. Lee, A. L. Osterheld, L. J. Suter, R. C. Mancini, C. F. Hooper, Jr, and N. D. Delamater, Phys. Fluids B 5, 3328 (1993).

${ }^{48}$ J. C. Kieffer, Y. Beaudoin, M. Chaker, C. Y. Cote, H. Pépin, C. Y. Chien, S. Coe, and G. Mourou, in X-ray Lasers, edited by E. E. Fill, IOP Conf. Proc. No. 125 (Institute of Physics and Physical Society, London, 1992), p. 201.

${ }^{49}$ J. C. Kieffer, J. P. Matte, S. Belair, M. Chaker, P. Auderbert, H. Pépin, P. Maine, D. Strickland, P. Bado, and G. Mourou, IEEE J. Quantum Electron. QE-25, 2640 (1989).

${ }^{50}$ H. Milchberg, I. Lyubonuisky, and G. G. Durfee, Phys. Rev. Lett. 67, 2654 (1991).

${ }^{\text {s1 }}$ Ya. B. Zel'dovich and Yu. P. Raizer, in Physics of Shock Waves and High Temperature Hydrodynamic Phenomena (Academic, New York, 1967), p.652.

${ }^{52}$ M. D. Rosen, Proc. SPIE 1229, 60 (1990).

${ }^{53}$ S. Ethier, J. P. Matte, J. C. Kieffer, M. Chaker, O. Peyrusse, and M. Büsquet, Bull. Am. Phys. Soc. 39, 1366 (1994).

${ }^{54}$ H. Chen, B. Soom, B. Yaakobi, S. Uchida, and D. D. Meyerhofer, Phys. Rev. Lett. 70, 3431 (1993).

${ }^{55}$ A. Rousse, P. Audebert, J, P. Geindre, F. Falliès, J. C. Gauthier, A. Mysyrowicz, G. Grillon, and A. Antonetti, Phys. Rev. E 50, 2200 (1994).

${ }^{56}$ J. C. Kieffer, H. Pépin, and F. Amiranoff, Appl. Phys. Lett. 44, 494 (1984).

${ }^{57}$ N. A. Dyson, X-ray in Atomic and Nuclear Physics (Langman Group Limited, London, 1973), p. 62.

${ }^{58}$ C. Dick, J. Metz, R. Placious, and J. Sparrow, J. Appl. Phys. 44, 815 (1973).

${ }^{59}$ L. V. Spencer, Phys. Rev. 98, 1597 (1955).

${ }^{60}$ U. Teubner, J. Bergmann, B. Van Wanterghem, F. P. Schafer, and R. Sauerbrey, Phys. Rev. Lett. 70, 794 (1993).

${ }^{61}$ J, D. Kmetec, G. L. Gordon, III, J. J. Macklin, B. E. Lemoff, G. S. Brown, and S. E. Harris, Phys. Rev. Lett. 68, 1527 (1992). 